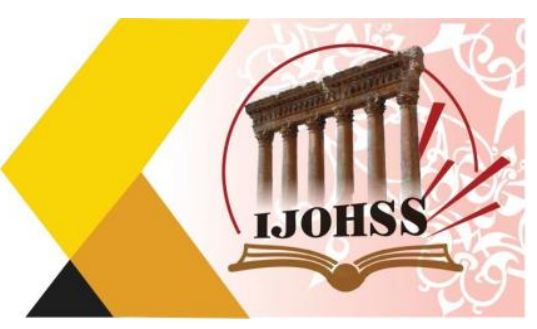

\title{
ظاهرة الإعراب بين التيسير والتشديد عند القدماء و والمحدثين
}

\author{
م.د. قعم العلوم موسيى حسينة \\ كلية القانون و العلوم السياسية ـ الجامعة العراقية \\ العراق
}

Ammarmousa850@gmail.com

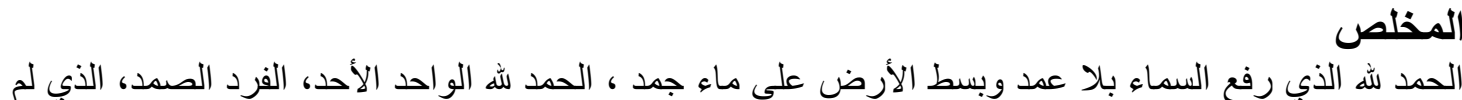

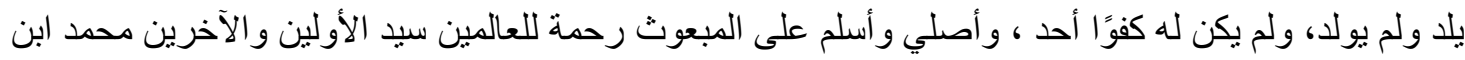

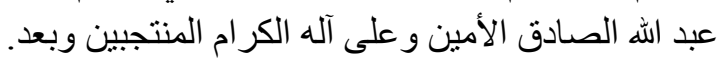

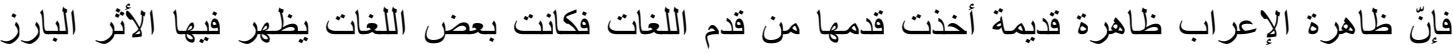

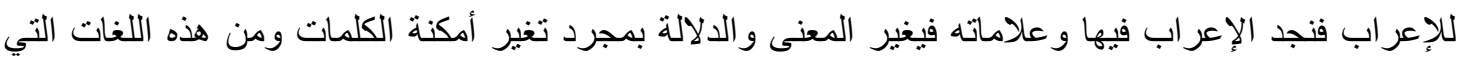

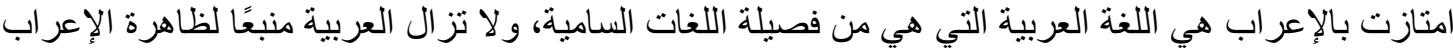

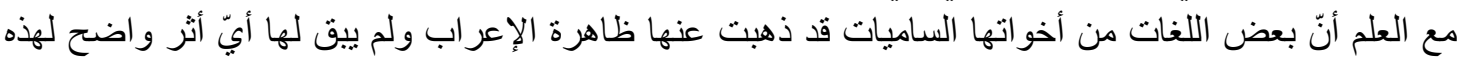

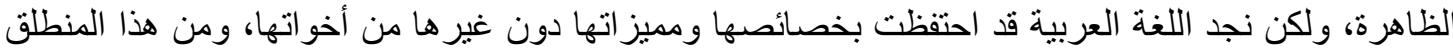

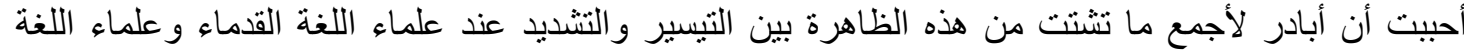

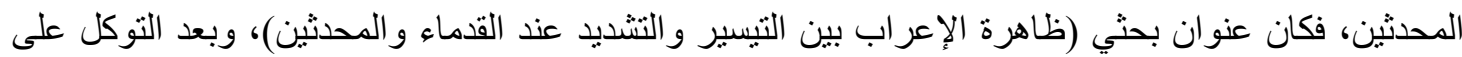

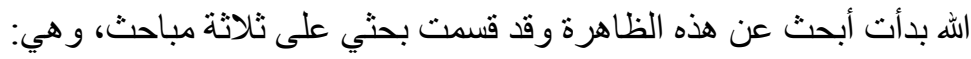

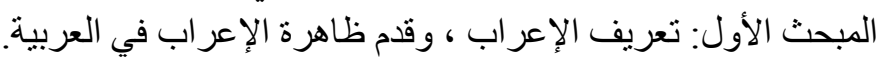
المبحث الثاني: دعوات التيسير عند المحدثين وظاهرة الإعراب. المبحث الثالث: آر اء العلماء حول ظاهرة الإعراب و تأثير ها في المعنى.

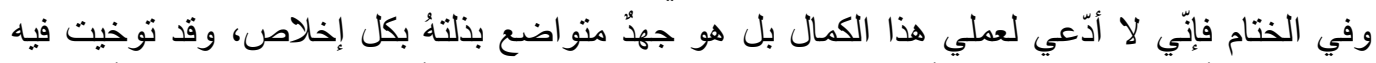

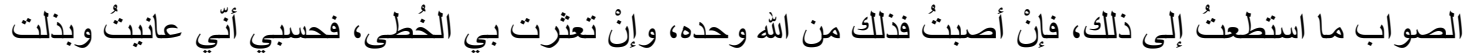
الجهد، و الحمد لله أولًا وآخرًا. 


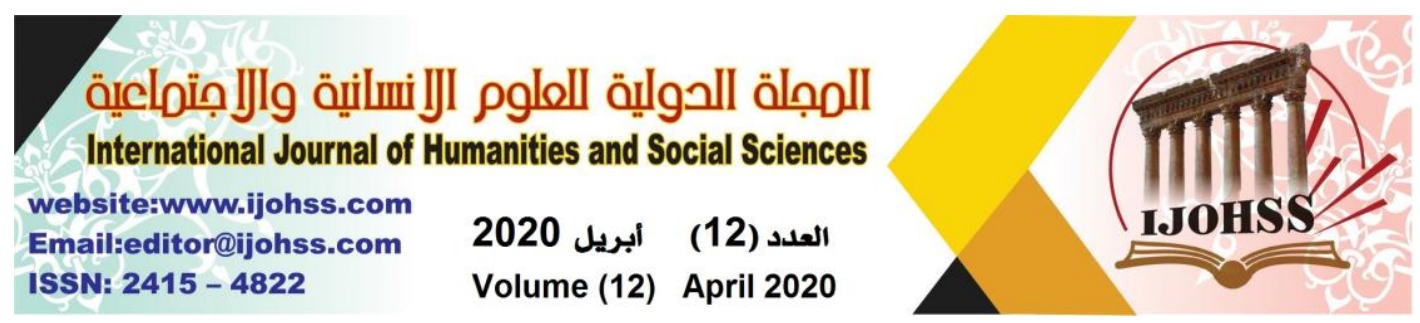

\title{
The Phenomenon of Parsing Between Facilitation and Tightening For The Ancient and the Modern
}

\author{
Dr. Ammar Musa Hussein \\ College of Law and Political Science \\ Iraqi University \\ Iraq \\ Ammarmousa850@gmail.com
}

\begin{abstract}
Praise is to God, who raised the sky without intentionally, and spread the earth to frozen water. Praise is to God, the One, the one who has survived, who did not give birth nor was born, nor had enough people. Distinguished and honored. The phenomenon of expression is an old phenomenon that was introduced by the oldest languages. Some languages showed the prominent effect of the expression, and we find the expression in it and its signs, so the meaning and significance change once the places of words change. And from these languages that were distinguished by the Arabic language, which is a sublime language of the Semitic languages, Arabic is still a source of the phenomenon Expressing, knowing that some languages of her Semitic sisters have gone away from the phenomenon of Arabization and have no remaining impact of this phenomenon, but we find the Arabic language has retained its characteristics and advantages without other sisters, and from this standpoint I wanted to initiate to collect what is dispersed from this phenomenon with me N Facilitation and emphasis among the ancient linguists and modern linguists, so the title of my research was (the phenomenon of parsing between facilitation and emphasis among the ancient and modern), and after relying on God, I began looking for this phenomenon and I divided my research into three topics, namely:

The first topic: Definition of Arabization, and introduced the phenomenon of Arabization in Arabic.

The second topic: facilitation calls for the modernizers and the phenomenon of parsing.

The third topic: the opinions of scholars on the phenomenon of parsing and its effect on meaning.

In conclusion, I do not claim to do this perfection, but rather it is a humble effort I made with all sincerity, and I envisioned the rightness of what I could to do so, if I hit that from God alone, and if the sin stumbled on me, then I thought that I suffered and exerted the effort, praise be to God first and foremost.
\end{abstract}

Keywords: Parsing, Arabic. 


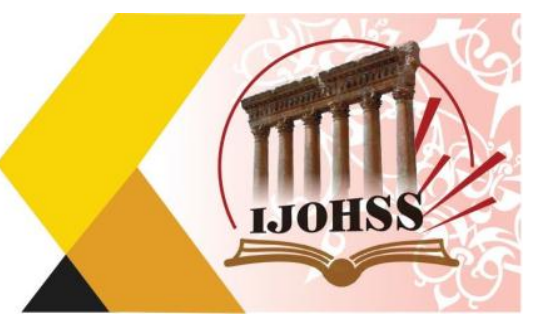

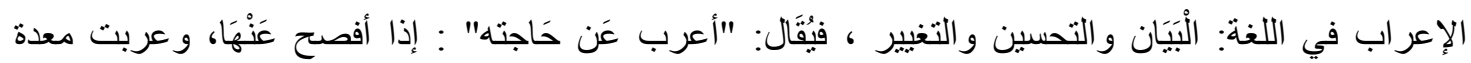

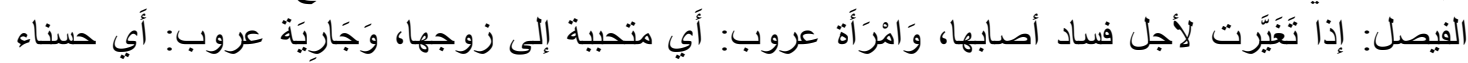

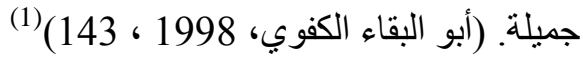

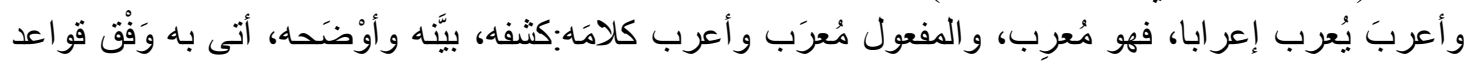

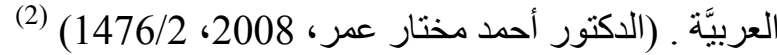

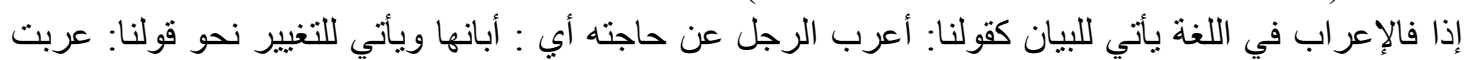

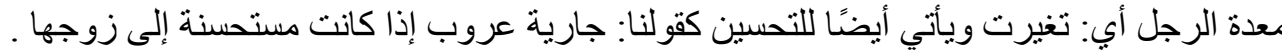

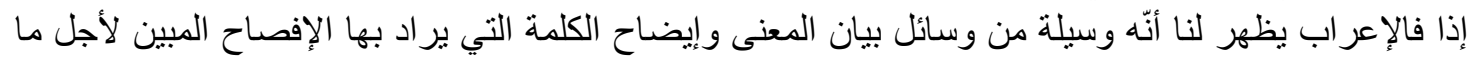

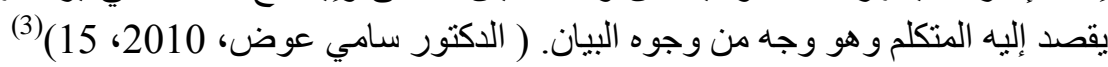

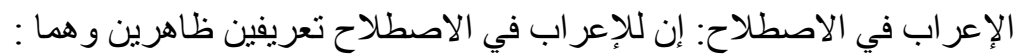

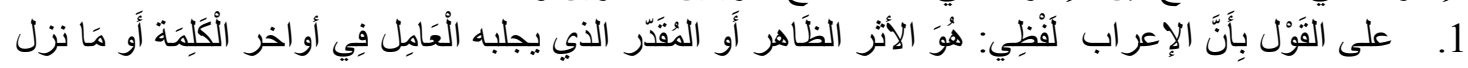
مَنْزْلَتَه. 2

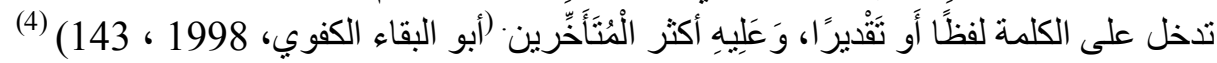

قام ظاهرة الإعراب في العربية فقد ذهب أكثر العلماء إلى أنّ العربية هي إحدى اللغات السامية التي ظلت محتفظة بسمات متعددة أخذتها من اللغة

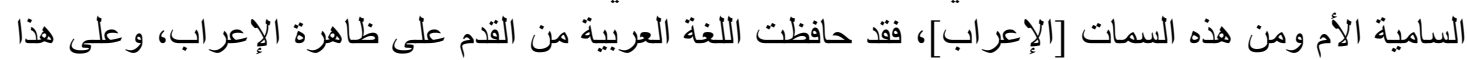

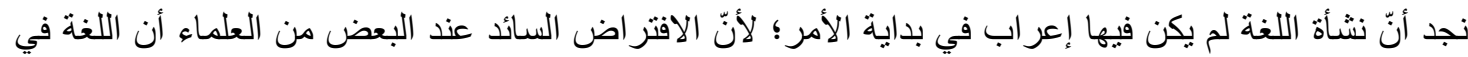

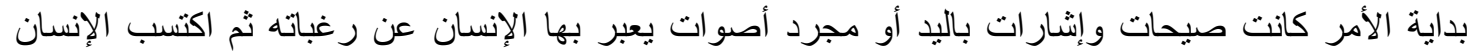

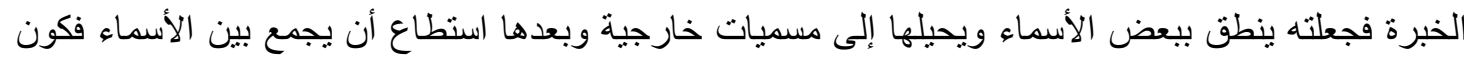

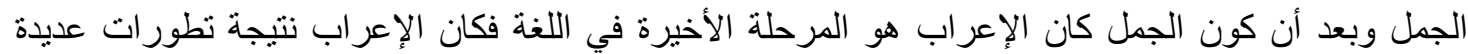

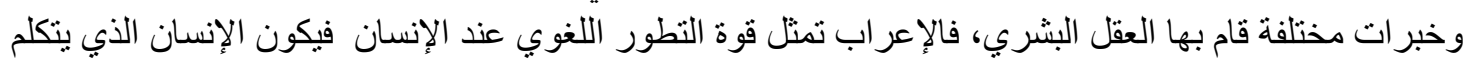

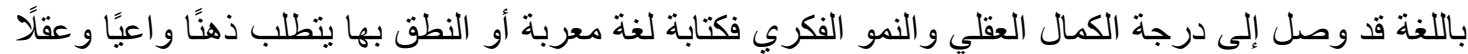

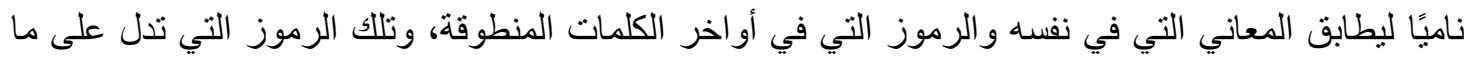

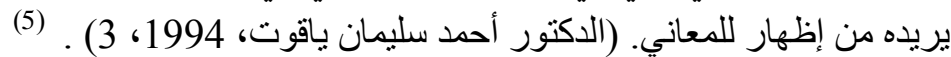

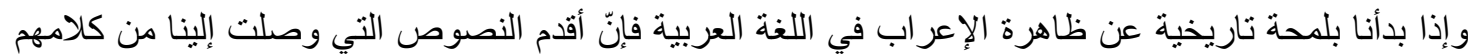

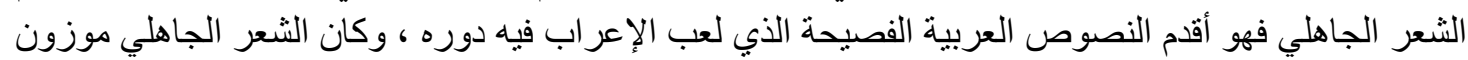

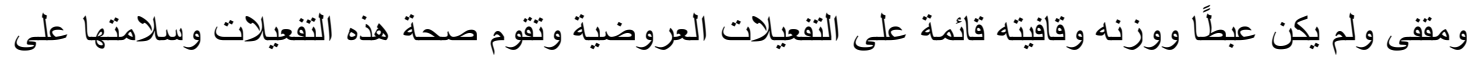

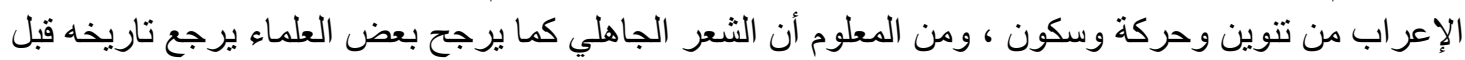

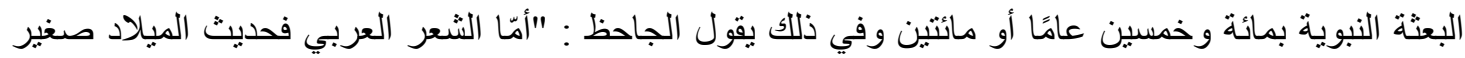

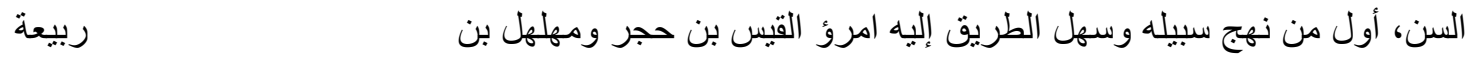

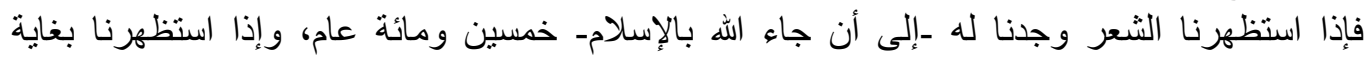

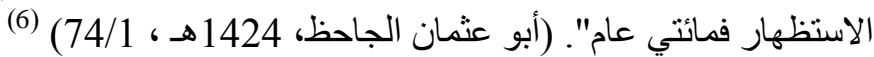




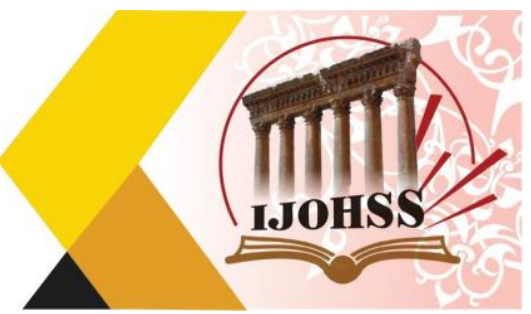

و إذا أردنا تتبع ظاهرة الإعراب فنخرج عن الثعر الجاهلي إلى اللغة السامية الأم فنجد أنّ من أهم أركانها

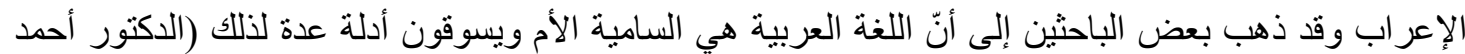

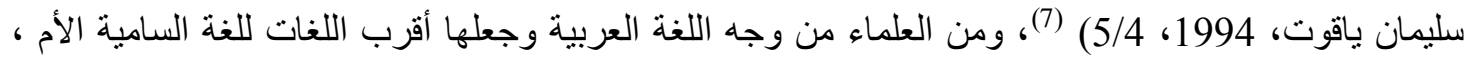

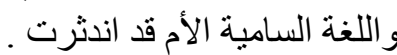

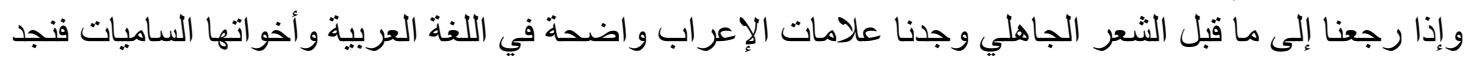

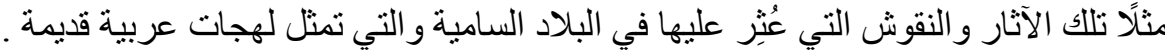

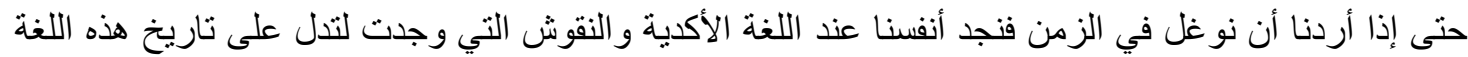

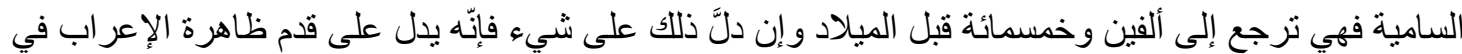

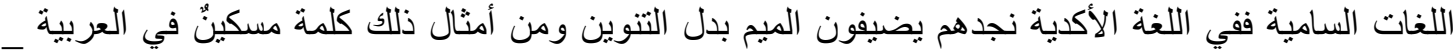

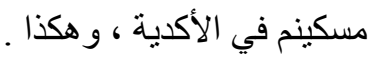
و لا أريد أن أطيل في إثبات قدم ظاهرة الإعر اب في اللغة لأنّ هذا ما لا يخفى على أحد من الناس .

دور أبي الأسود والخليل في وضع علامات الإعراب لم تغفل علامات الإعراب قبل تدوين اللغة فهي كانت موجودة متداولة على الإبل السنة العرب الفصحاء ولم يكونوا

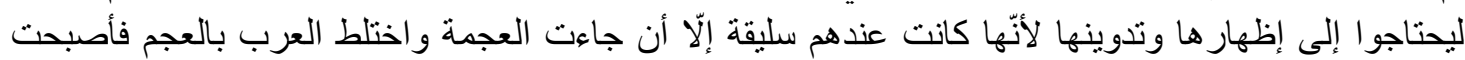

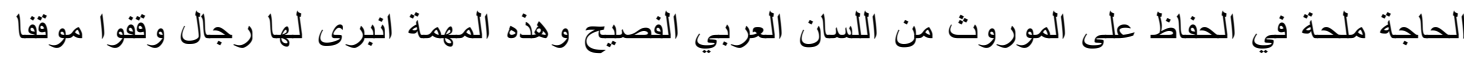

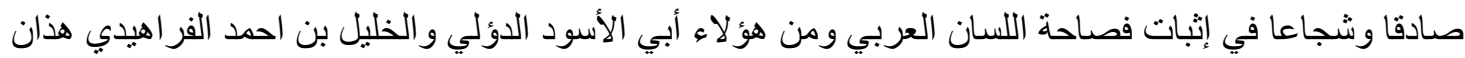

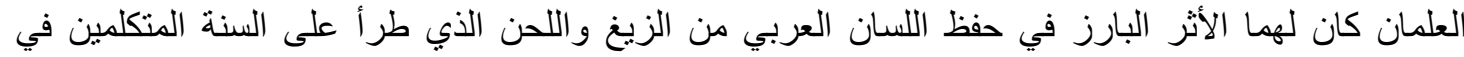

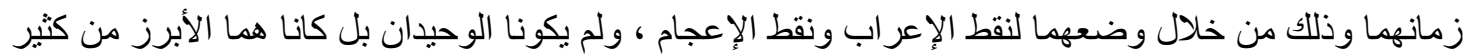

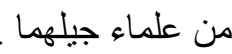

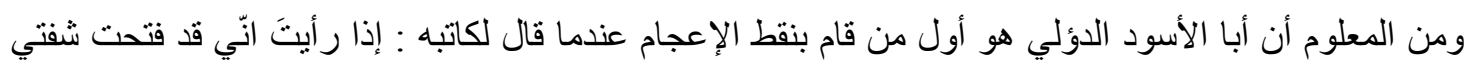

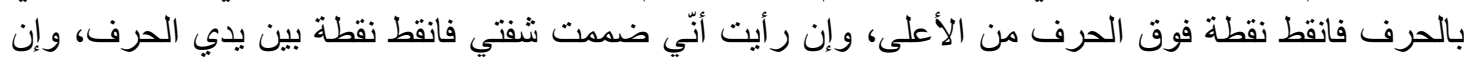

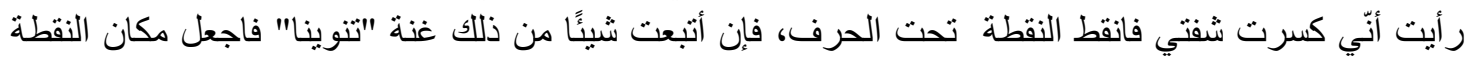

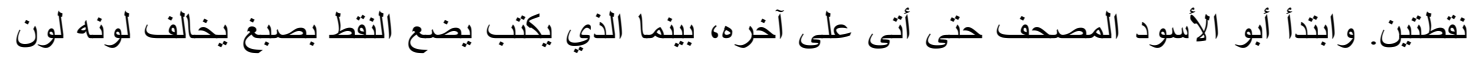

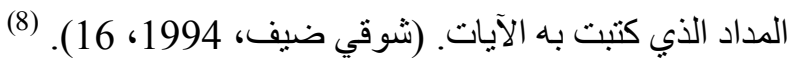

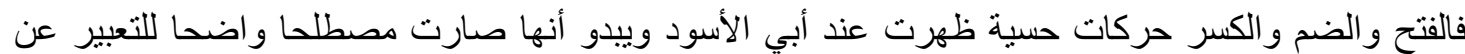

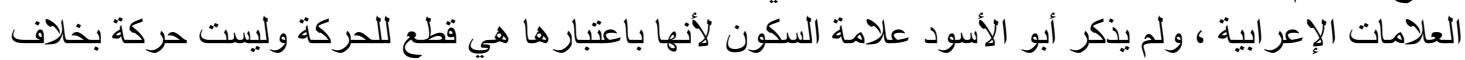

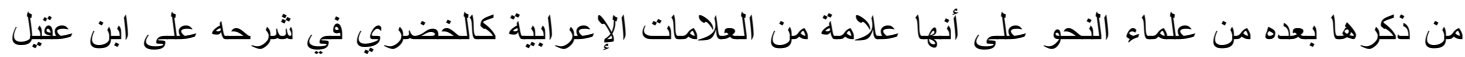

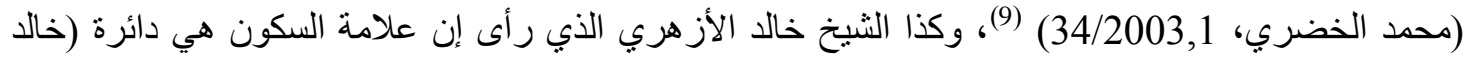

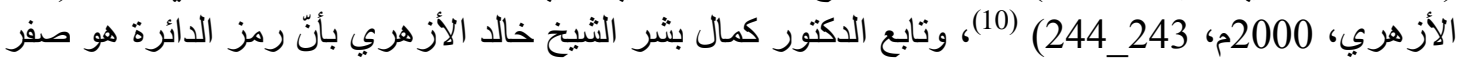

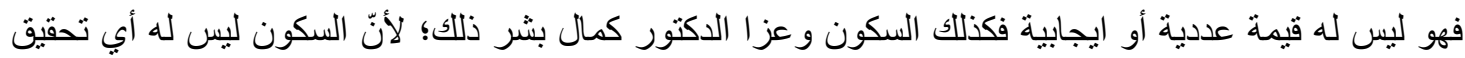

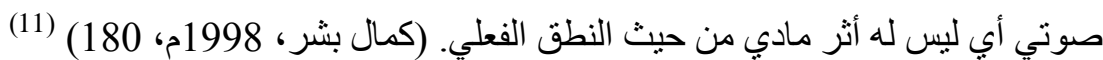

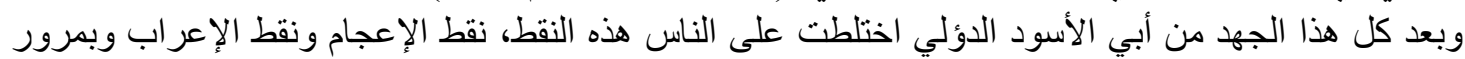

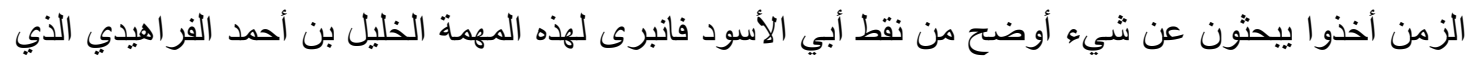

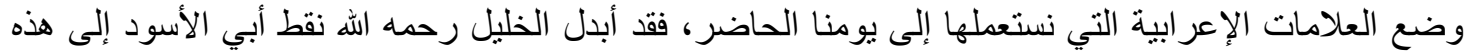

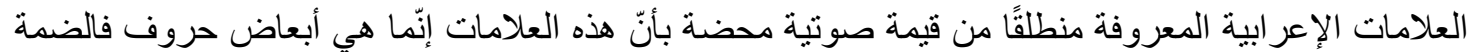

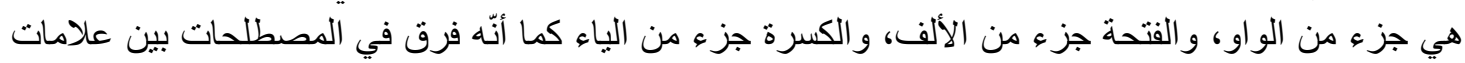

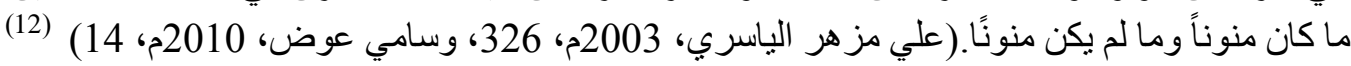




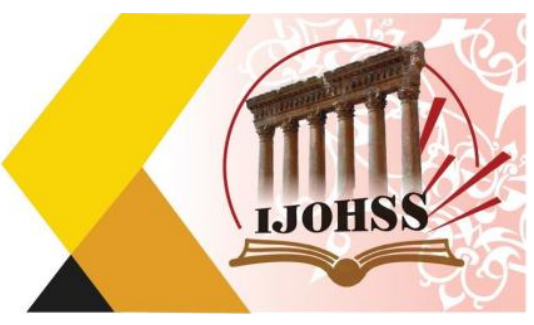

\section{دعوات التيسير عند القدماء والمحثثيث الثانيث وظاهرة الإعراب}

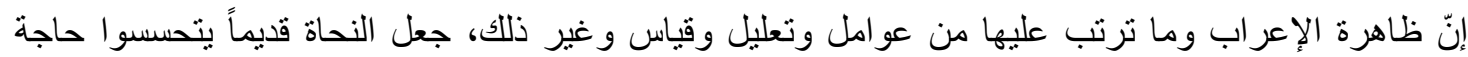

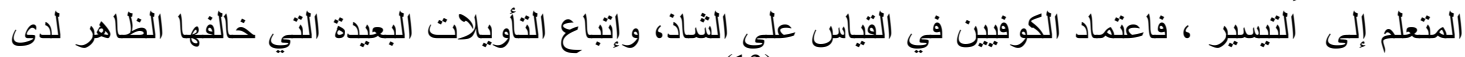

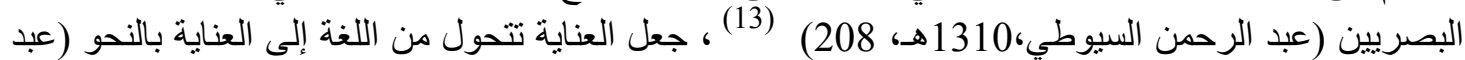

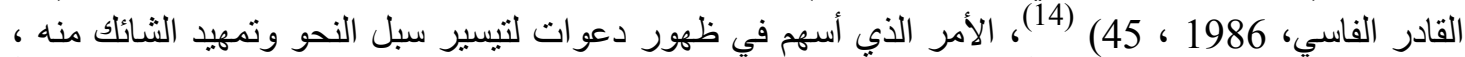

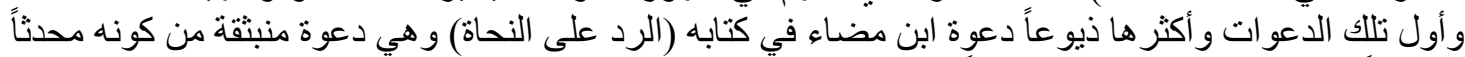

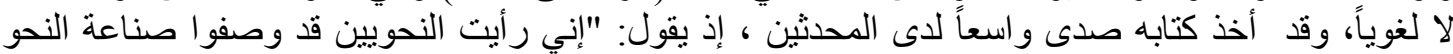

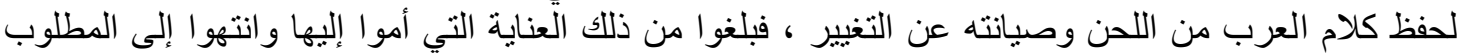

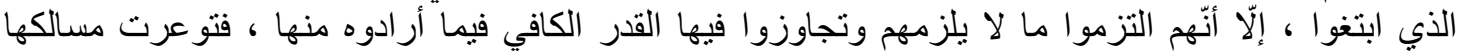

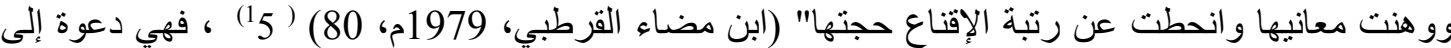

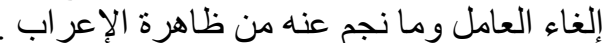

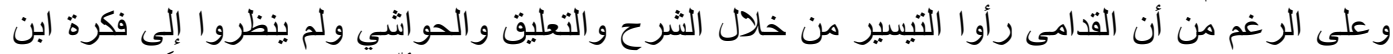

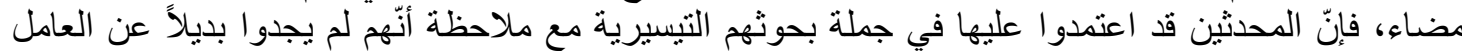

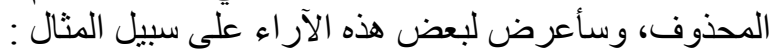

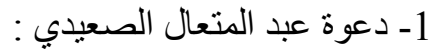

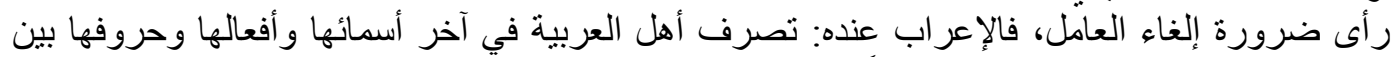

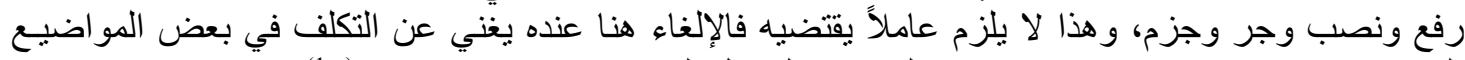

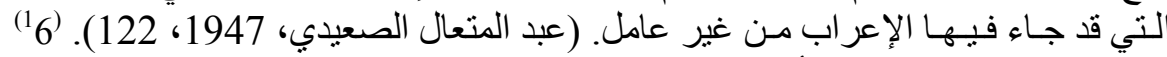

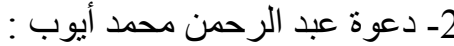

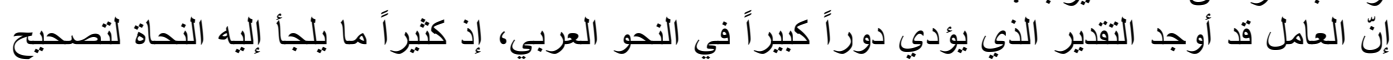

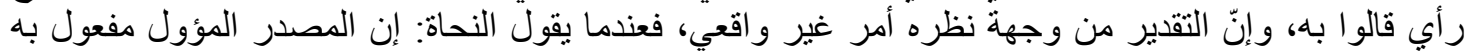

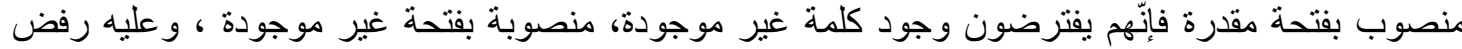

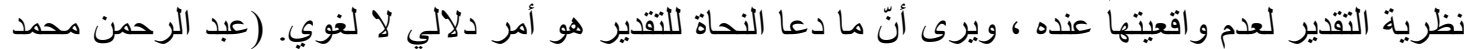

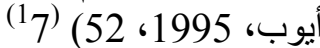

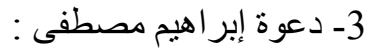

يعد من أو ائل الداعين إلى إلغاء نظرية العامل من المحدثين من دون أن يعتمد في ذلك على آلى آراء علماء الثاء اللغة

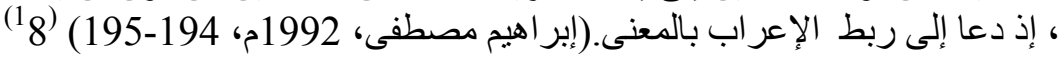

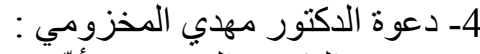

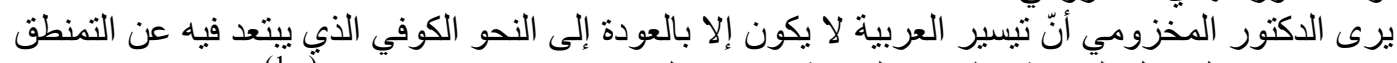

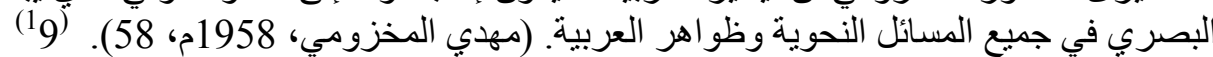

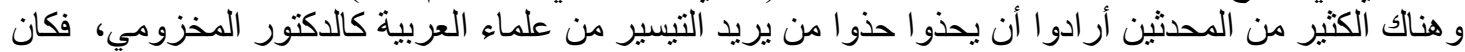

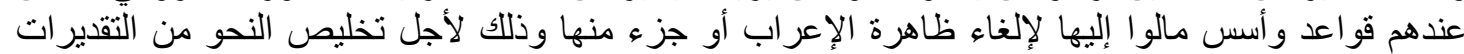

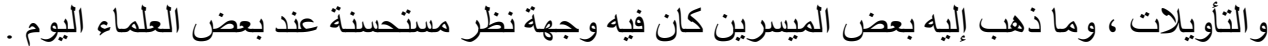

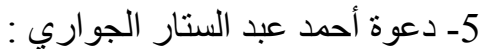

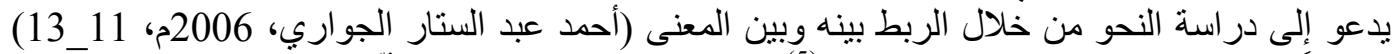

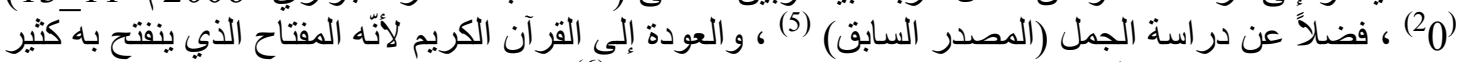

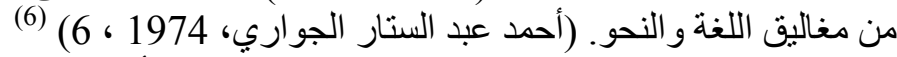

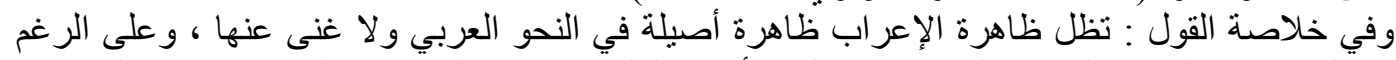

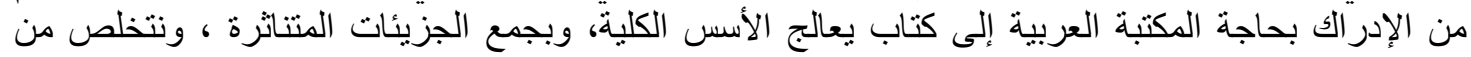




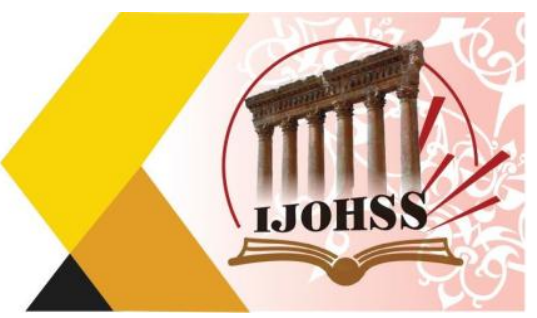

التفريعات غير الضرورية ، فإنّي أجد في كتب عدد من الباحثين إنباعاً لتلك الحاجة و لاسيما من جمع في كتابه

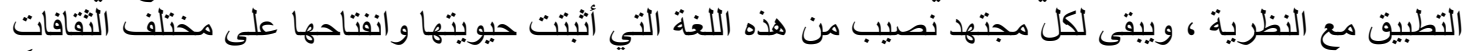

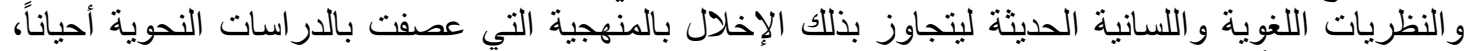

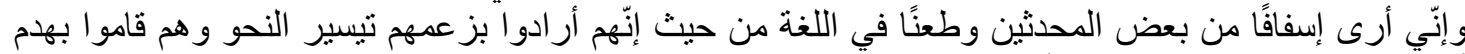

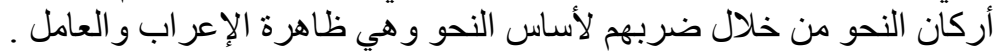

\section{المبحث الثالث \\ آراء العلماء حول ظاهرة الإعراب وتأثثير ها في المعنى}

تناولت هنا آراء العلماء حول ظاهرة الإعراب و هل لها تأثنير في المعنى حيث نجد هم انقسموا إلى فريقين:

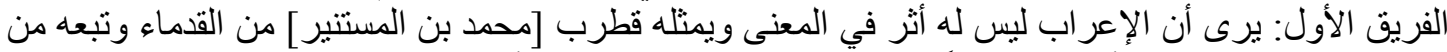

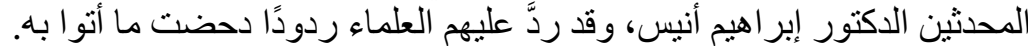

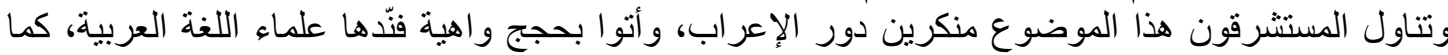

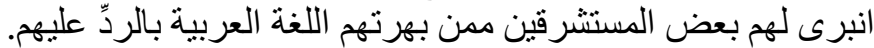

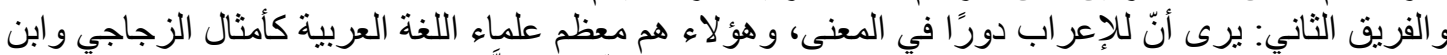

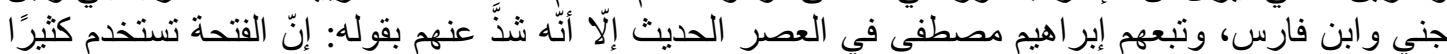

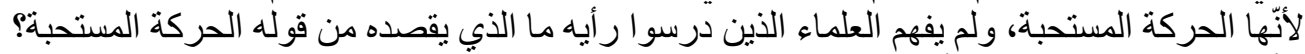

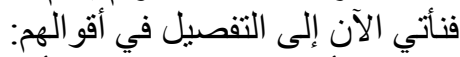

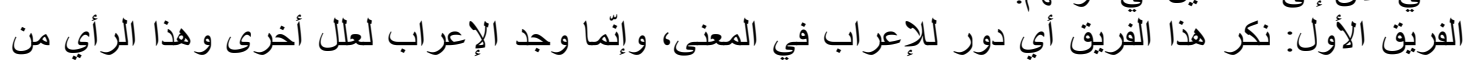

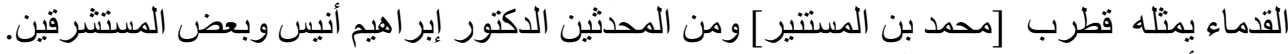

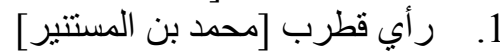

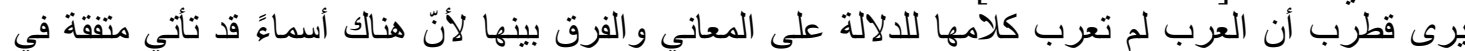

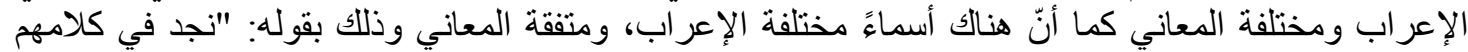

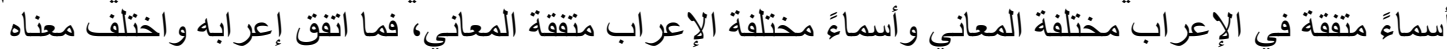

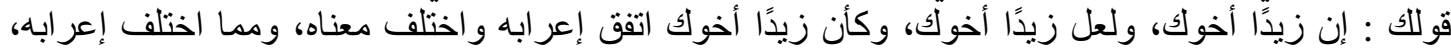

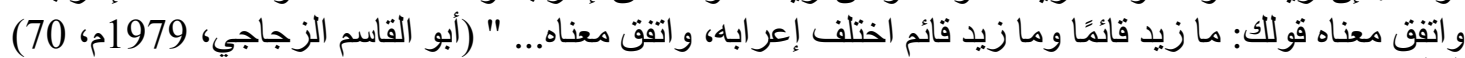

وله رأي آخر يرى فيه أنّ هذه الحركات جيء بها للسرعة في الكلام وللتخلص من التقاء الساكنين عند اتصال التهال

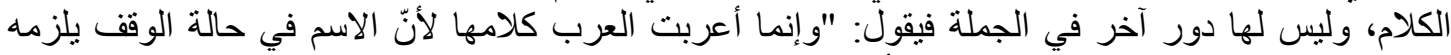

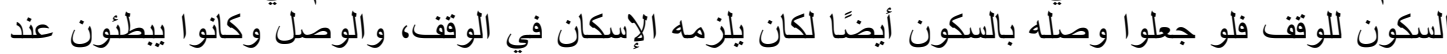

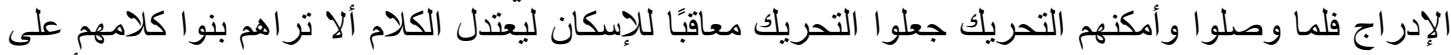

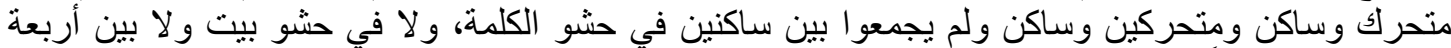

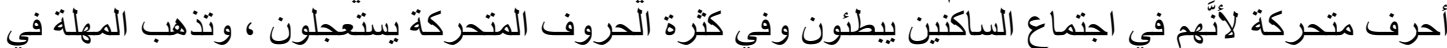

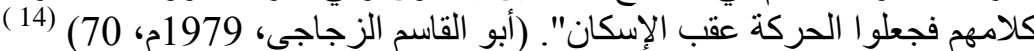

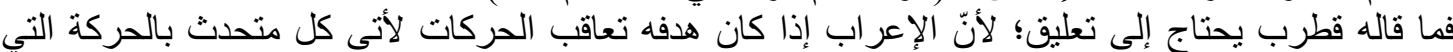

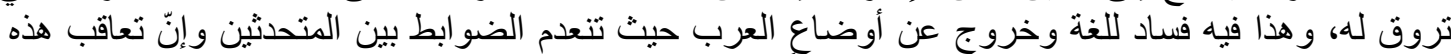

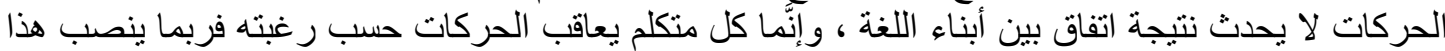

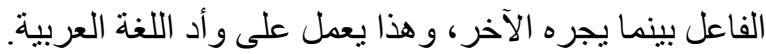

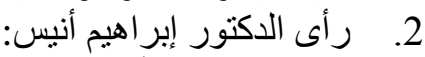

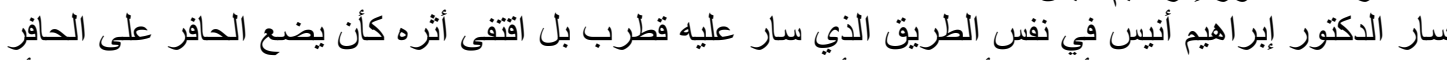

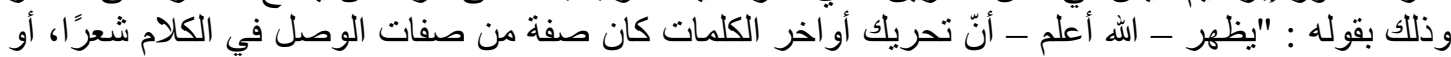

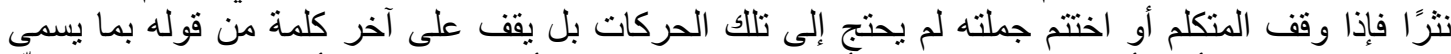

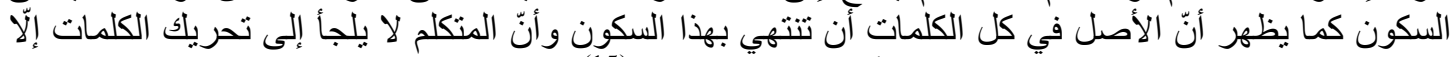

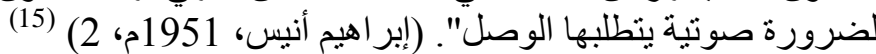




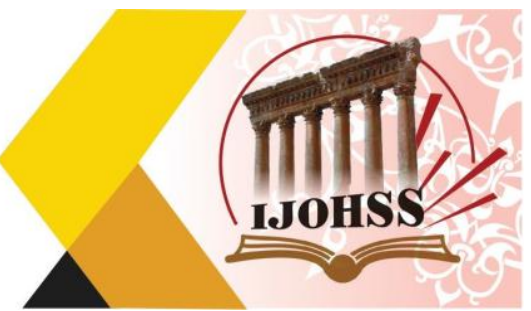

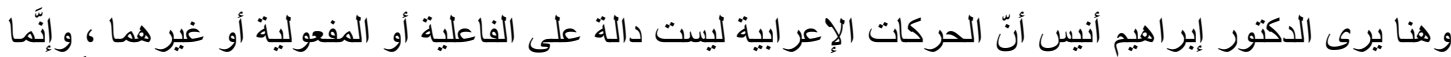

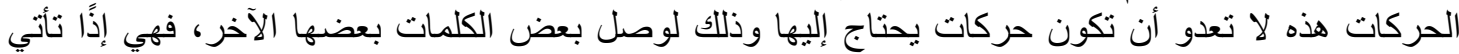

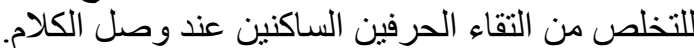

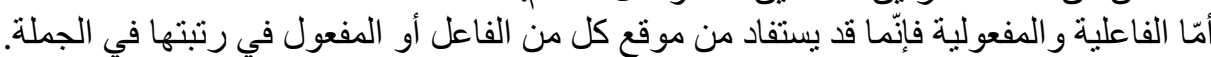

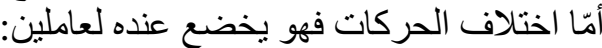
الأول: الإيثار و هو إيثار بعض الحروف لحركة معينة دون غير ها كايثار حروف الحلق للفتحة سأل يسأل.

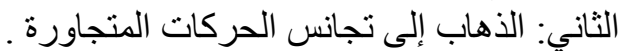

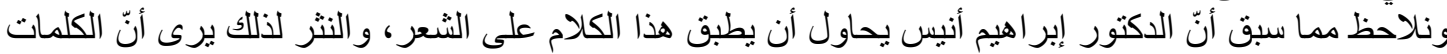

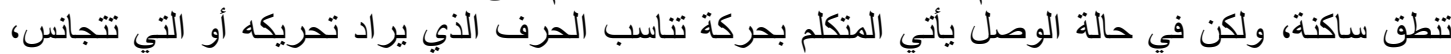

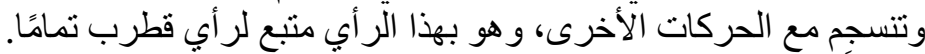

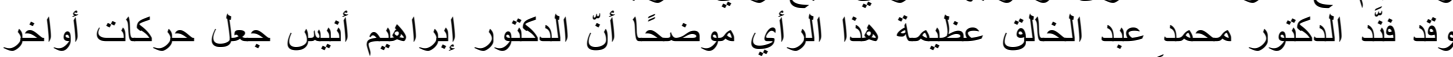

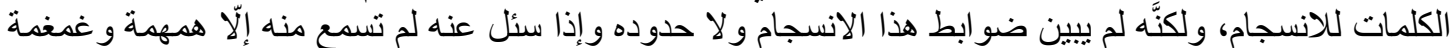

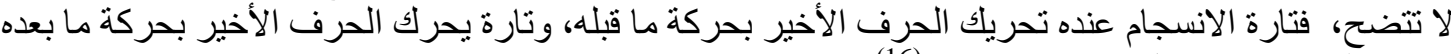

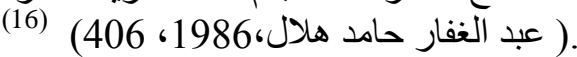

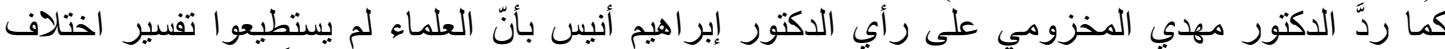

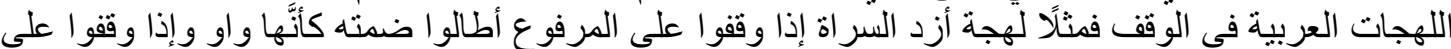

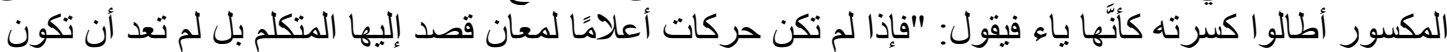

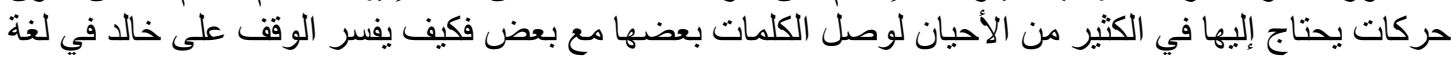

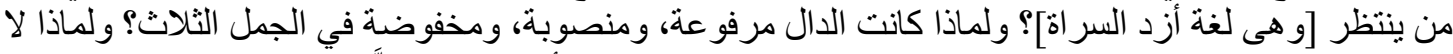

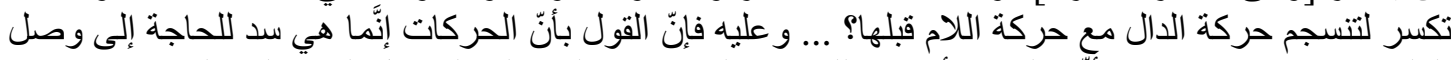

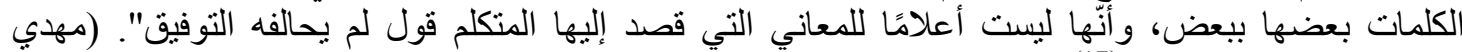

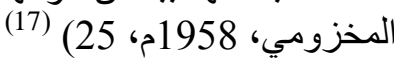
ويتضح من خلال هذه الردود التي سقناها أنّ قطرب وإبرا اهيم أنبس لم يوفقا في الحصول على غايتهما في هدم

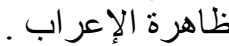

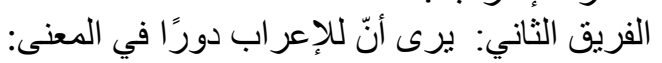

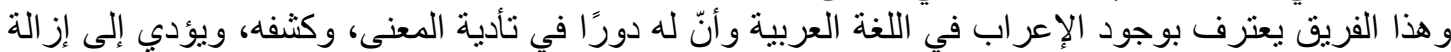

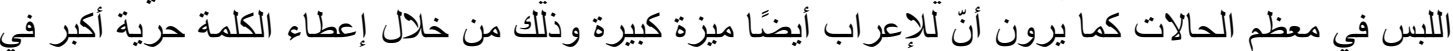

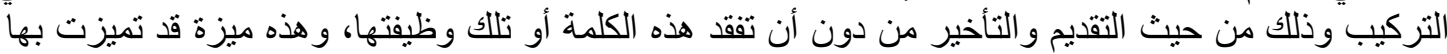

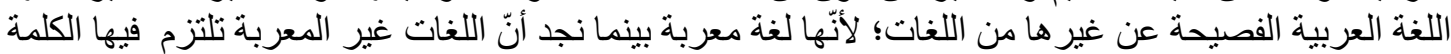

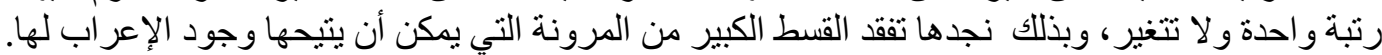

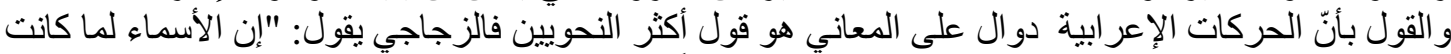

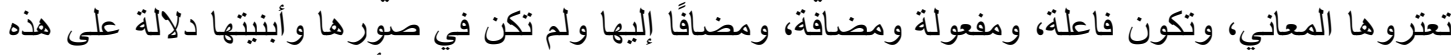
المعاني بل كانت مشتركة جعلت حركات الإعراب فيها تتبئ عن هذه المعاني " . (أبو القاسم الزجاجي، 1979 1979م،

فهو يرى أنّ هذه الأسماء تأتي فاعلة ومفعولة و غيرها وليس فيها ما يدل عليها، أو يميز بينها إلّا الإعراب حيث

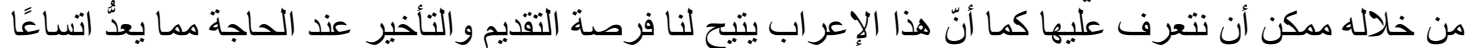
في اللغة.

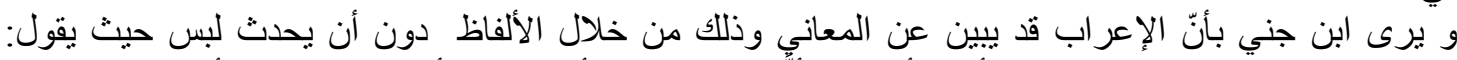

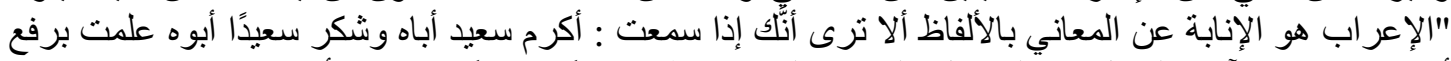

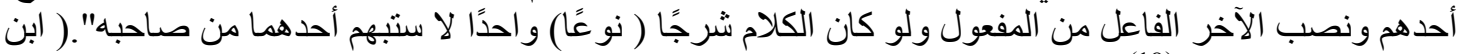

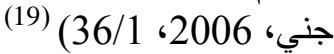
فالتقديم و التأخير من أهم الميزات التي أتاحها الإعراب للغة العربية، ولو لاه لما استطاع الدارس التمييز بين الفاعل

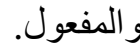




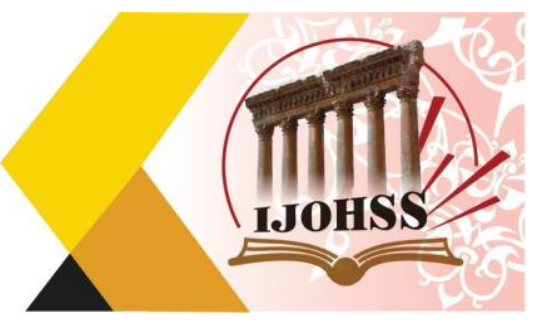

الخاتمة وأهم النتائج

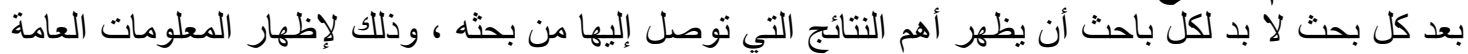

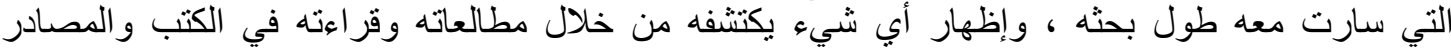
و المر اجع و البحوث ، فأستعين بالله و أقول:

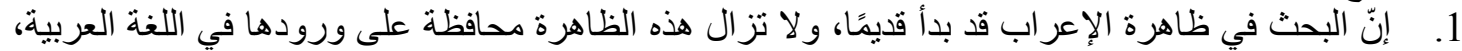

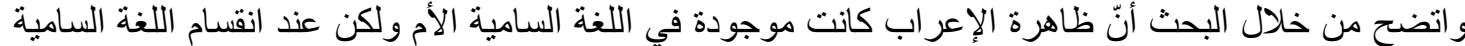

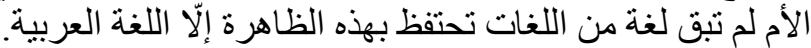

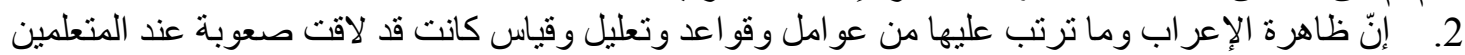

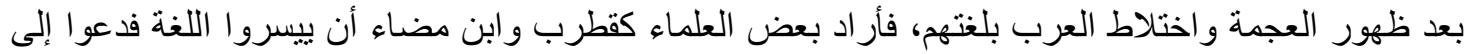

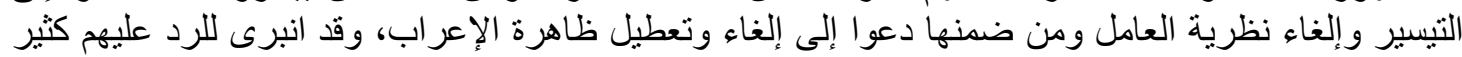
من علماء اللغة.

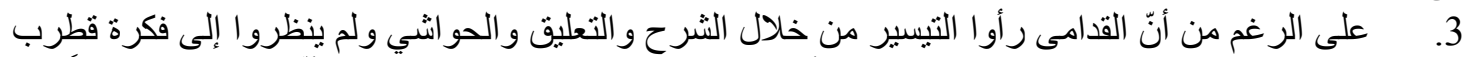

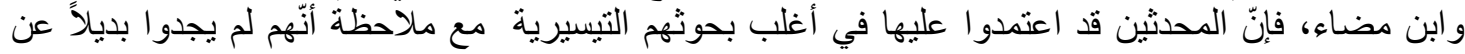
العامل المحذوف.

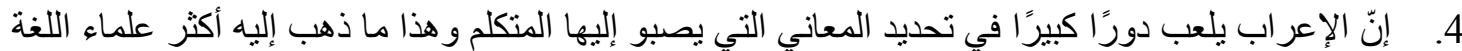

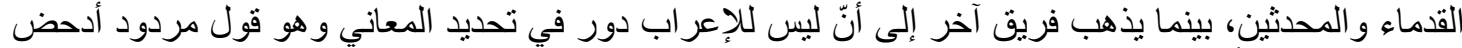
بالأدلة النقلية فضلًا عن العقلية.

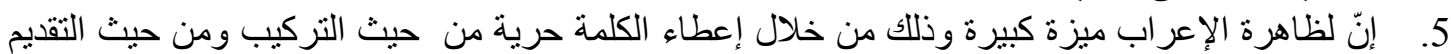

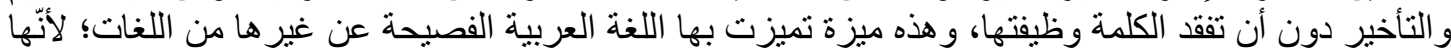

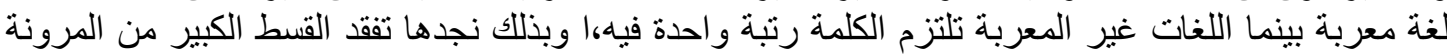

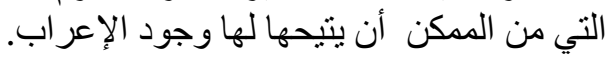

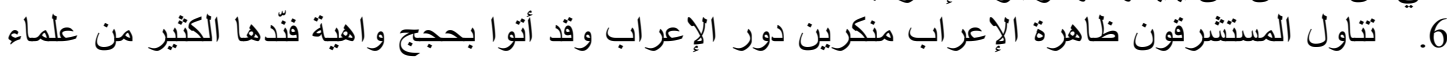

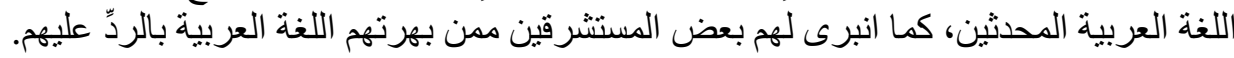




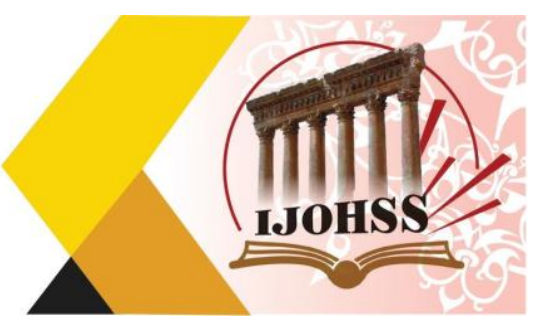

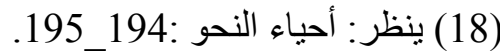
(19) ينظر : مدرسة الكوفة ومنهجها في در اسة اللغة و النحو: 8 و.

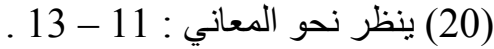

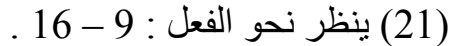
.

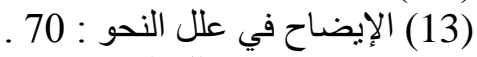

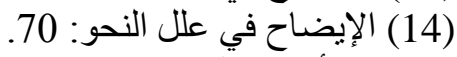

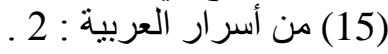
(16) ينظر : علم اللغة بين القديم و الحديث: 7 ـ ـ ع.

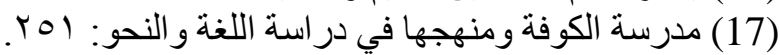
69 : 69 (18) الإيضانصاح

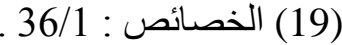

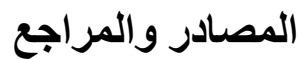

1. إبر اهيم مصطفى (المنوفى 1382 هـ ) ، سنة الطبع: 1413هـ _ 1992 م، إحباء النحو، الناثر : دار

2. أبو البقاء أيوب بن موسى الحسيني القريمي الكفوي، الحنفي (المتوفى: 1094هـ)، سنة الطبع:

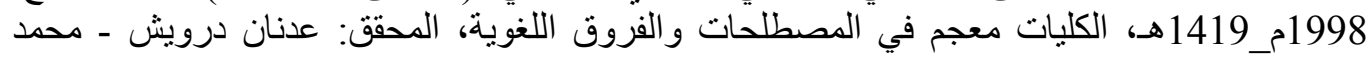

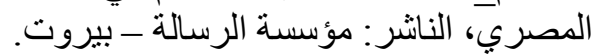

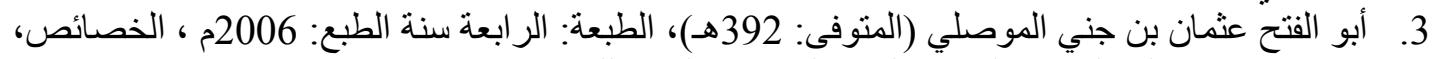
تحقيق : محمد علي النجار ، النانر : الهيئة المصرية العيد العامة للكتاب.

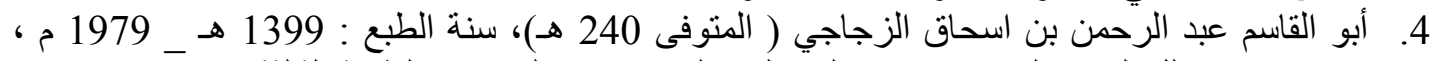

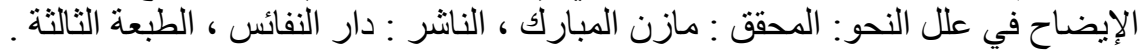

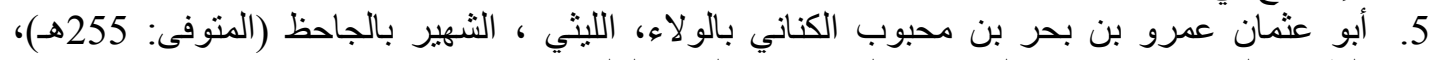

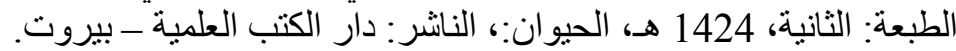

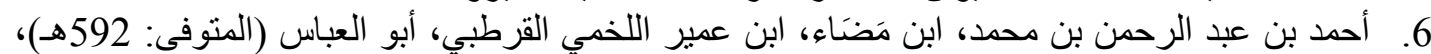

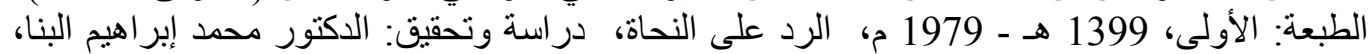

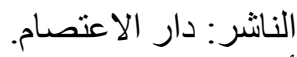

7. أحمد شوفي عبد السلام ضيف الأنيف الثهير بشوقي ضيف (المتوفى: 1426هـ)، سنة الطبع: 1968م، الددارس

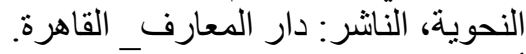

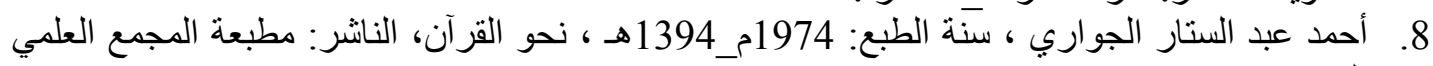
9. أحمد عبد الستار الجواري ، سنة الطبع: 2006م، نحو المعاني، الناشر : المؤسسة العربية للدراسات

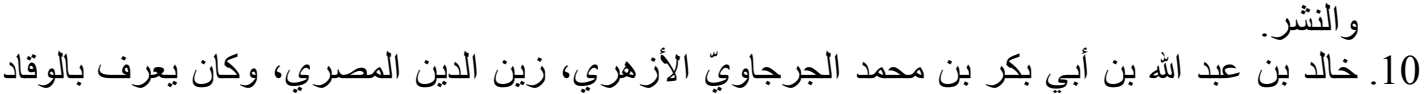

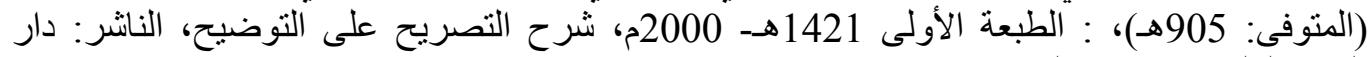

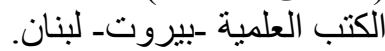
11. الدكتور إبراهيم أنبس من أسرار العربية، الطبعة : الثالثة، سنة الطبع: 901 ام، الناثر : مكتبة الأنجلو 12. الدكتور أحمد سليمان باقوت، سنة الطبع : 1994 م، ظاهرة الإعراب في النحو العربي وتطبيقها في القرآن الكريم، الناشر : دار المعرفة الجامعية. 


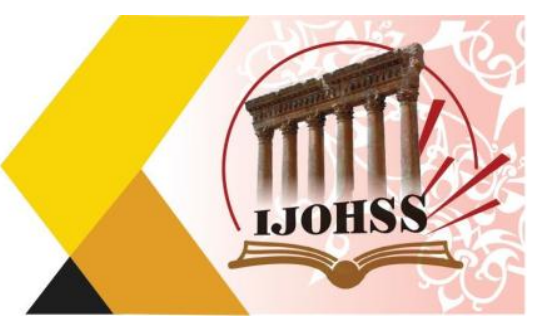

13. الدكتور سامي عوض ، المجلد (32) العدد (2) سنة : 2010 م ، ظاهرة الإعراب وموقف علماء إهاء العربية

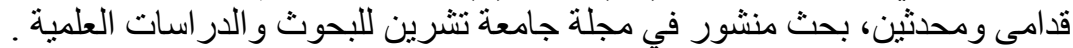

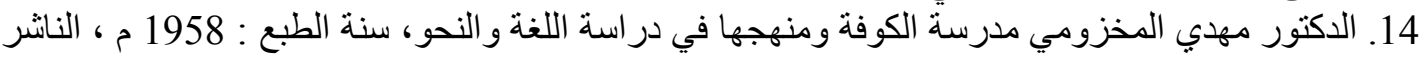
: مطبعة مصطفى الحلبي. 15. الدكتور: أحمد مختار عبد الحميد عمر (المتوفى: 1424هـ)، الطبعة: الأولى، 1429 هـ - 2008 م، معجم

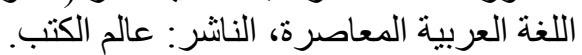

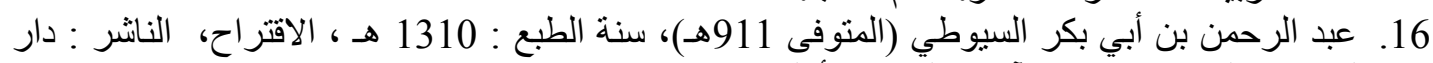

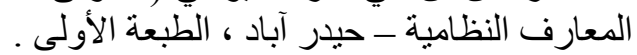

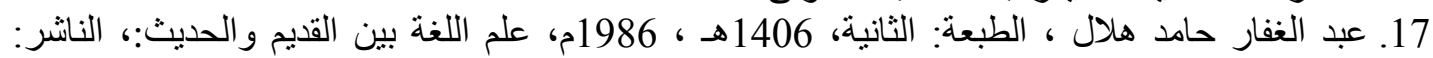
مطبعة الجيلاوي، القاهرة. 18. عبد القادر الفاني الفهري، ، سنة النشرة النشر: 1986م_1406هـ، اللسانيات و اللغة العربية، الناثر: دار طوبقال

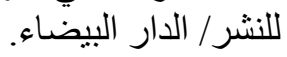

19. عبد المتعال الصعيدي، سنة الطبع : 1947 م ، النحو الجديد :، الناشر : دار الفكر العربي للطباعة والنشر

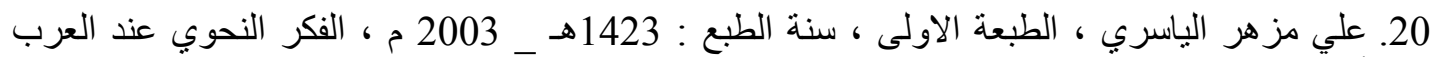

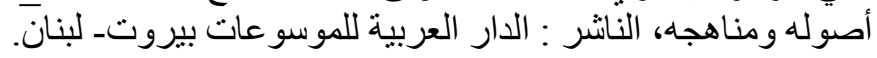

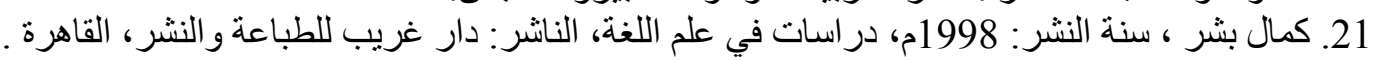

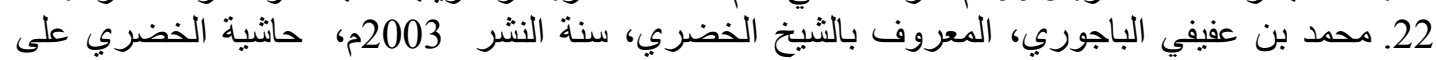
شرح ابن عقيل على الفية أبن مالك ، الناثر : دار الفكر للطباعة و النشر و التوزيع. 


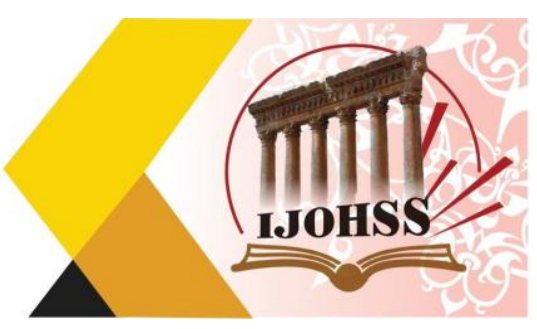

\section{References}

1. Ibrahim Mustafa (d. 1382 AH), year of publication: 1413 AH-1992 AD, revival of grammar, publisher: Dar Al-Fikr.

2. Abu al-Baqaa Ayoub bin Musa al-Husayni al-Quraimi al-Kafwi, al-Hanafi (died: 1094 AH), year of publication: 1998_1419 AH, colleges glossary of terms and linguistic differences, investigator: Adnan Darwish - Muhammad al-Masri, publisher: Al-Risala Foundation - Beirut.

3. Abu al-Fath Othman bin Jani al-Musli (died: $392 \mathrm{AH}$ ), edition: the fourth year of publication: $2006 \mathrm{AD}$, characteristics, investigation: Muhammad Ali al-Najjar, publisher: the Egyptian General Book Authority.

4. Abu al-Qasim Abd al-Rahman ibn Ishaq al-Zajaji (died $240 \mathrm{AH}$ ), year of publication: 1399 AH-1979 AD, clarification of grammar grammar: Investigator: Mazen Al-Mubarak, Publisher: Dar Al-Nafees, third edition.

5. Abu Othman Amr bin Bahr bin Mahboub Al-Kanani loyalty, Al-Leithi, famous for Al-Jahiz (died: $255 \mathrm{AH}$ ), edition: second, 1424 AH, animal:, publisher: Dar AlKutub Al-Alami - Beirut.

6. Ahmed bin Abd al-Rahman bin Muhammad, Ibn Mada`, Ibn Umair al-Lakhmi alQurtubi, Abu al-Abbas (died: 592 AH), edition: first, 1399 AH - 1979 AD, response to grammar, study and investigation: Dr. Muhammad Ibrahim al-Banna, publisher: Dar al-I'tisam.

7. Ahmad Shawqi Abdul Salam Dhaif, famous as Shawqi Dhaif (died: $1426 \mathrm{AH}$ ), year of publication: 1968 CE, grammar schools, publisher: Dar Al-Maarif_Cairo.

8. Ahmed Abdul-Sattar Al-Jawary, year of publication: 1974 AD_1394 AH, Towards the Qur'an, Publisher: Iraqi Scientific Complex Press.

9. Ahmad Abdul Sattar Al-Jawary, year of publication: 2006 AD, Towards meanings, publisher: Arab Foundation for Studies and Publishing.

10. Khalid bin Abdullah bin Abi Bakr bin Muhammad al-Jarjawi al-Azhari, Zain alDin al-Masri, and he was known as al-Waqqad (d.

11. Dr. Ibrahim Anis from the secrets of Arabia, edition: the third, year of publication: $1951 \mathrm{AD}$, publisher: The Anglo-Egyptian Library.

12. Dr. Ahmad Suleiman Yaqout, year of publication: 1994, the phenomenon of Arabization in Arabic grammar and its application in the Holy Qur'an, publisher: Dar Al-Marefa Al-Jami'ia.

13. Dr. Sami Awad, volume (32), issue (2) year: 2010, the phenomenon of parsing and the position of Arab scholars old and new, a research published in Tishreen University Journal for Research and Scientific Studies.

14. Dr. Mahdi Al-Makhzoumi School of Kufa and its approach to the study of language and grammar, year of publication: 1958 AD, publisher: Mustafa Al-Halabi Press. 


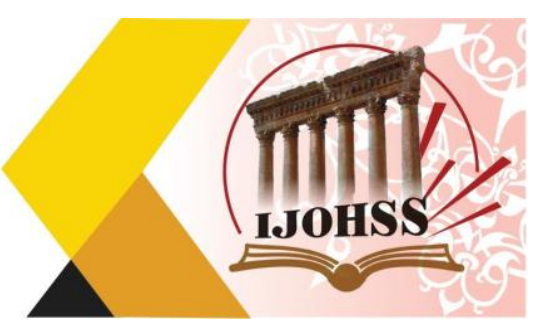

15. Dr.: Ahmed Mokhtar Abdel Hamid Omar (died: 1424 AH), Edition: First, 1429 AH - 2008 AD, Contemporary Arabic Language Dictionary, Publisher: World of Books.

16. Abd al-Rahman ibn Abi Bakr al-Suyuti (died 911 AH), year of publication: 1310 AH, al-Qarathah, publisher: Dar al-Ma'arif al-Nizamiyya - Hyderabad, first edition.

17. Abdel-Ghaffar Hamed Hilal, Edition: Second, 1406 AH, 1986 AD, Linguistics between the ancient and the modern :, Publisher: Al-Jailawi Press, Cairo.

18. Abd al-Qadir al-Fassi al-Fihri, Publication year: 1986 AD - 4040 AH, Linguistics and the Arabic Language, publisher: Toubkal Publishing House / Casablanca.

19. Abdel Mutaal Al-Saidi, year of publication: 1947 AD, the new grammar:, publisher: Dar Al-Fikr Al-Arabi for printing and publishing.

20. Ali Mezher Al-Yasiri, First Edition, Printing Year: 1423 AH-2003 AD, Grammatical Thinking among Arabs Its Origins and Methods, Publisher: The Arab Encyclopedia, Beirut - Lebanon.

21. Kamal Bishr, Publishing Year: 1998 AD, Studies in Linguistics, Publisher: Dar Gharib for Printing and Publishing, Cairo.

22. Muhammad bin Afifi Al-Bagouri, known as Sheikh Al-Khudari, published in the year 2003 AD, footnote to Al-Khudari Ali Sharh Ibn Aqeel on Alfiya Ibn Malik, publisher: Dar Al-Fikr for printing, publishing and distribution. 